\title{
EVALUASI KEBIJAKAN SISTEM ZONASI DALAM SELEKSI PENERIMAAN PESERTA DIDIK BARU (PPDB) TINGKAT SEKOLAH MENENGAH ATAS DI KOTA PEKANBARU
}

\author{
Difa Cucu Sabrina ${ }^{1}$ Ishak $^{2}$ \\ 1,2 Jurusan Ilmu Pemerintahan, Fakultas Ilmu Sosial dan Ilmu Politik, Universitas Riau \\ Email :diffacucu@yahoo.co.id
}

\begin{abstract}
ABSTRAK
Penerimaan peserta didik baru dengan kebijakan sistem zonasi telah diberlakukan di Kota Pekanbaru, Provinsi Riau. Melalui Peraturan Kementrian Pendidikan dan Kebudayaan Republik Indonesia Nomor 20 Tahun 2019 kebijakan ini berlaku di seluruh Dinas Pendidikan Kabupaten/Kota di Indonesia. Penerapan kuota zonasi sebesar 80 persen oleh pemerintah Kota Pekanbaru menimbulkan banyak pro dan kontra. Tujuan kebijakan sistem zonasi dalam PPDB yakni untuk mengurangi biaya transportasi pendidikan, mendekatkan calon peserta didik dengan domisili tempat tinggal nya, mengurangi kemacetan, serta menghilangkan persepsi sekolah favorit dan tidak favorit juga dengan utama adalah pemerataan pada kualitas pendidikan. Penelitian ini menggunakan metode penelitian deskriptif kualitatif dengan subjek penelitian tingkat sekolah menengah atas di Kota Pekanbaru. Teknik pengumpulan data menggunakan wawancara, observasi dan dokumentasi. Hasil Penelitian ini menunjukkan bahwa peran Dinas Pendidikan dan Pemerintah Daerah Kota Pekanbaru, dalam mengevaluasi kebijakan sistem zonasi untuk PPDB tingkat SMA belum terlaksana secara maksimal, hal tersebut karena kurangnya sosialisasi oleh penyelenggara kebijakan sehingga tidak menimbulkan pemahaman yang komprehensif terhadap masyarakat.
\end{abstract}

Kata Kunci: Evaluasi Kebijakan, Sistem Zonasi, Peran

\section{PENDAHULUAN}

Penerimaan peserta didik baru (PPDB) dengan menggunakan sistem zonasi sudah tepat karena berlandaskan pancasila. Namun, sistem zonasi tersebut harus disertai pula dengan peran dari negara dalam memberikan keadilan. Sistem zonasi merupakan hasil manisfestasi dari penyelenggaraan pendidikan yang berpilar pada nilai-nilai pancasila terutama pada kemanusiaan dan keadilan dalam merealisasikan tatanan rekrutmen siswa. Sistem zonasi juga di harapkan akan meringankan beban orangtua yang memiliki tingkat perekonomian rendah.

Setiap tahun sistem yang dipakai untuk penerimaan siswa baru selalu menjadi sorotan. Karena sistem yang digunakan untuk melakukan penerimaan murid baru ini selalu menyediakan masalah bagi orang tua siswa yang menginginkan sekolah negeri.

Dalam penyelenggaraan penerimaan murid baru tingkat sekolah menengah atas, sistem berpedoman pada Peraturan Menteri 
Pendidikan dan Kebudayaan yakni Nomor 20 Tahun 2019 tentang Penerimaan Peserta Didik Baru Pada Taman Kanak-Kanak, Sekolah Dasar, Sekolah Menengah Pertama, Sekolah Menengah Atas, dan Sekolah Menengah Kejuruan.[1]

Pada pasal 16 ayat (2), penulis menarasikan kembali bahwa jalur zonasi mendapatkan kuota sebanyak $80 \%$ dari daya tampung yang dimiliki sekolah dengan berarti seluruh sekolah yang berada di bawah wewenang pemerintah wajib mengalokasikan kuota untuk murid baru yang berdomisili di dekat sekolah sebesar $80 \%$. Hal tersebut dianggap melanggar Undang-Undang No 20 Tahun 2003 Tentang Sistem Pendidikan Nasional[2] pada Pasal 51 ayat (1) yang di narasikan kembali oleh penulis bahwa dalam pengelolaan satuan pendidikan di usia dini, dan pendidikan menengah perlu mendasar pada standar pelayanan minimal yang berprinsip pada manajemen berbasis sekolah/madrasah.

Sistem penerimaan siswa/murid baru tingkat Sekolah Menengah Atas adalah salah satu manajemen berbasis sekolah/madrasah. Semestinya pemerintah pusat tidak ikut mengendalikan otonomi tersebut dengan mengeluarkan peraturan yang ditetapkan dalam skala nasional tetapi pemerintah pusat harusnya memberikan pedoman yang mana akan membuat suatu tindakan lebih mudah di prediksi dan akan menghasilkan kualitas yang lebih baik. Menetapkan presentase sebesar $80 \%$ dianggap tidak memberi kesempatan kepada anak yang mempunyai kepandaian tetapi lokasi tempat tinggalnya jauh dari sekolah negeri.

Dikutip dari Riau.com pada (1 November 2019) [3] bahwa di sisi lain, penyelenggaraan sistem penerimaan murid baru tingkat sekolah menengah atas dengan jalur zonasi sangat didukung oleh masyarakat yang tinggal dekat dengan zonasi sekolah, juga Kepala Dinas Pendidikan Kota Pekanbaru, yaitu Bapak Abdul Jamal. Penerapan jalur zonasi mewajibkan calon siswa untuk menempuh pendidikan adalah yang memiliki radius paling dekat yakni 500 meter dari domisilinya masing-masing. Penyelenggaraan sistem zonasi ini dianggap akan menyamaratakan pendidikan, memberikan fasilitas-fasilitas kepada sekolah yang kurang berdaya dan mengurangi pungutan-pungutan tertentu di sekolah favorit serta menutup celah kecurangan dalam administrasi penerimaan murid baru di tiap-tiap sekolah. Upayaupaya yang dilakukan ini adalah untuk pemerataan akses dan kualitas pendidikan nasional. Namun dari upaya yang dilakukan serta banyaknya keluhan atas terselenggaranya sistem zonasi di Kota Pekanbaru, ternyata sistem zonasi masih perlu di evaluasi.

Evaluasi menurut Stufflebeam et.al (1971) (dalam Daryanto, 1999:1)[4] Evaluation is the process of delineating, obtaining, and providing useful information for judging decision alternatives". Maksudnya adalah evaluasi yakni teknik untuk menggambarkan, memdapatkan dan mengemukakan informasi yang berguna untuk menilai alternatif dari sebuah keputusan. 
Evaluasi yang dilakukan pemerintah adalah dengan memberikan pilihan kepada siswa-siswa yang tidak mendapatkan sekolah negeri untuk ke sekolah swasta dengan alasan agar sekolah swasta tidak sepi peminat, dan memiliki kualitas yang relatif lebih baik. Evaluasi ini sangat merugikan masyarakat yang kurang mampu juga telat mendaftarkan anaknya ke sekolah negeri padahal memiliki kepandaian/prestasi. Lalu, ada evaluasi terhadap sosialisasi sistem zonasi yang sebenarnya masih kurang baik, evaluasi sosialisasi yang dilakukan masih menimbulkan banyak kontra pada masyarakat, dari tata cara pendaftaran sampai proses penerimaan masih membingungkan masyarakat seperti pada kejadian sebagian orangtua yang terpaksa menginap untuk memastikan anaknya diterima di sekolah yang dituju, fenomena ini membuktikan bahwa kurangnya gencarnya evaluasi sosialisasi terhadap regulasi sistem zonasi.

Oleh karena itu, zonasi sebagai salah satu metode penyeleksi merupakan kebijakan yang wajib di evaluasi oleh dinas pendidikan kota pekanbaru bersama pemerintah daerah karena menuai kontra dari berbagai belah pihak, adanya upaya dalam mengevaluasi yang sudah dilakukan justru membuat masyarakat semakin dilema dan atas kebijakan yang di ambil untuk menangani sistem zonasi.

Berdasarkan latar belakang dari permasalahan yang diuraikan, maka dapat dirumuskan masalah nya yakni :

1. Bagaimana peran dinas pendidikan kota pekanbaru dalam mengevaluasi permasalahan sistem zonasi tingkat sekolah menengah atas pada seleksi penerimaan murid baru di Kota Pekanbaru?

2. Bagaimana dampak pelaksanaan sistem zonasi terhadap pelaksanaan penerimaan peserta didik baru tingkat sekolah menengah atas di Kota Pekanbaru?

\section{KERANGKA TEORI}

\section{A. Evaluasi Kebijakan}

Menurut Lester dan Stewart (2000 : 126)[5] evaluasi bertujuan untuk menampakkan beberapa kegagalan dari suatu kebijakan dan untuk mengetahui apakah kebijakan yang telah dirumuskan dan diterapkan dapat menghasilkan impak yang di inginkan.

Dalam mengevaluasi kebijakan ada tiga pokok hal penting yang perlu diperhatikan, yakni :

- Evaluasi kebijakan berupaya untuk memberikan informasi yang valid tentang kinerja dari suatu kebijakan. Hal ini berguna untuk menilai cara dalam pelaksanaan) kebijakan dan menilai hasil dari penggunaan cara tersebut.

- Evaluasi kebijakan berupaya untuk menilai kepastian tujuan atau target dengan masalah yang sedang dihadapi. Upaya evaluasi kebijakan yakni untukmemfokuskan diri pada substansi dari kebijakan publik yang ada. Evaluasi harus menilai apakah tujuan yang telah ditetapkan oleh kebijakan tersebut benar-benar mampu menyelesaikan masalah 
1. NAKHODA:

JURNAL

ILMU PEMERINTAHAN
NAKHODA: JURNAL ILMU PEMERINTAHAN

Edisi Juli-Desember 2019 Volume: 18 Nomor: 2

ISSN : 1829-5827 | E-ISSN : 2656-5277

DOI : https://doi.org/10.35967/jipn

https://nakhoda.ejournal.unri.ac.id/index.php/JIPN yang ada.

- Evaluasi kebijakan juga berupaya untuk memberi ide pada kebijakan lain terutama dari segi metodologi. Artinya, evaluasi kebijakan diupayakan untuk menghasilkan rekomendasi dari penilaian yang dilakukan atas dasar kebijakan yang dievaluasi.

Menurut William Dunn (1999 : 608)[6], evaluasi kebijakan berkenaan dengan produksi informasi mengenai nilainilai atau manfaat-manfaat hasil kebijakan. Ada tiga fungsi evaluasi kebijakan, yaitu :

- Evaluasi kebijakan harus memberi informasi yang valid dan dipercaya mengenai kinerja kebijakan. Kinerja kebijakan yang dinilai dalam evaluasi kebijakan yakni : Pertama, seberapa jauh kebutuhan nilai, dan kesempatandapat dicapai melalui tindakan kebijakan/program.

Kedua, apakah tindakan yang ditempuh oleh implementing agencies sudah benar- benar efektif, responsif, akuntabel dan adil. Ketiga, bagaimana efek dan dampak dari kebijakan itu sendiri dengan evaluator yang dapat memberdayakan output dan outcome yang dihasilkan dari suatu hasil implementasi

kebijakan.

- Evaluasi kebijakan berfungsi memberi sumbangan pada klarifikasi dan kritik terhadap nilainilai yang mendasari pemilihan tujuan dan target. $\begin{array}{lrr}\text { Evaluasi } & \text { kebijakan } & \text { berfungsi } \\ \text { memberi } & \text { sumbangan } & \text { pada }\end{array}$ aplikasi metode analisis kebijakan lainnya, baik perumusan masalah maupun rekomendasi kebijakan.

Evaluasi kebijakan berguna untuk memperoleh fakta yang sebenar-benarnya dan mengukur pengaruh kebijakan. Tetapi mengevaluasi kebijakan tidaklah sederhana, ada beberapa permasalahan yang berkaitan dengan evaluasi kebijakan, seperti :

- Ketidakpastian arah/tujuan kebijakan.

- Hubungan sebagian akibat (causality)

- Pengaruh penerapan kebijakan yang meluas

- Sukarnya mendapatkan data

- Antipati pejabat kantor (official Resistance)

\section{B. Sistem Zonasi}

Sistem ini dikeluarkan oleh Kementrian Pendidikan dan kebudayaan melalui sebuah peraturan yakni Nomor 20 Tahun 2019 tentang Penerimaan Peserta Didik Baru pada Taman Kanak-Kanak, Sekolah Dasar, Sekolah Menengah Pertama, Sekolah Menengah Atas, Sekolah Menengah Kejuruan dan di aplikasikan dalam penyelenggaraan pada penerimaan peserta didik baru pada tahun ajaran 2019/2020.

Berdasarkan Kamus Besar Bahasa Indonesia (KBBI), arti kata zonasi adalah pendistribusian suatu area menjadi beberapa bagian, sesuai dengan fungsi dan 
tujuan pengelolaan. Sistem zonasi merupakan syarat utama dalam seleksi penerimaan murid baru dengan memperhatikan jarak antara tempat tinggal calon murid dan sekolah sesuai dengan Kartu Keluarga atau (KK) yang dikeluarkan minimal enam bulan sebelum seleksi penerimaan peserta didik baru diselenggarakan di Kota Pekanbaru.

\section{Landasan filosofis}

Sesuai Undang-Undang Republik Indonesia Nomor 20 Tahun 2003 tentang sistem pendidikan nasional, pasal 1 ayat (21), adanya evaluasi pendidikan berguna sebagai kegiatan pengendalian, penjaminan, penetapan mutu pendidikan terhadap berbagai komponen pendidikan di setiap jalur, jenjang, dan jenis pendidikan yang mana sebagai bentuk pertanggungjawaban atas penyelenggaraan pendidikan.

Dengan mendasar pada nawa cita Presiden Joko Widodo dan Jusuf Kalla, tujuan perkembangan potensi peserta didik agar mampu menjadi manusia Indonesia yang berkualitas, sistem zonasi dikembangkan menggunakan filosofi sebagai berikut:

- Menaikkan level hidup manusia indonesia

- Mengembangkan indonesia dari pinggiran dengan memperkuat daerah-daerah dan desa dalam kerangka negara kesatuan

- Meningkatkan produktivitas dan daya bersaing di pasar internasional

- Menggarap revolusi karakter bangsa
Oleh karena itu, Joko Widodo dalam Zonasi sebagai nawa cita berpendapat bahwa sistem zonasi dalam penerimaan peserta murid baru merupakan salah satu upaya pemerataan akses pada layanan dan kualitas pendidikan hingga ke daerahdaerah, serta melayani kelompok yang rendan dan terpinggirkan.

\section{Landasan Yuridris}

Menurut Undang-Undang No 12 Tahun 2011 yang membahas Pembentukan Peraturan Perundang-undangan Lampiran I dan II, Suatu peraturan yang dibentuk untuk mengatasi konflik hukum dengan mempertimbangkan aturan yang telah ada, yang akan diubah, bahkan memutuskan guna menjamin kepastian hukum dan rasa keadilan masyarakat. Sistem zonasi dalam penyelenggaraan penerimaan peserta didik baru berlandaskan pada :

- Undang - Undang Dasar Negara Republik Indonesia Tahun 1945

- Undang - Undang Nomor 20 Tahun 2003 Tentang Sistem Pendidikan Nasional

- Peraturan Menteri Pendidikan dan Kebudayaan Republik Indonesia Nomor 20 Tahun 2019 Tentang Perubahan Atas Peraturan Menteri pendidikan dan kebudayaan Nomor 51 Tahun $2018 \quad$ Tentang Penerimaan Peserta Didik Baru Pada Taman Kanak-Kanak, Sekolah Dasar, Sekolah Menengah Pertama, Sekolah Menengah Atas, Dan Sekolah Menengah Kejuruan.

- Surat Edaran Nomor 01 Tahun 2019 dan Nomor 420/2973/SJ 


\section{Tuntutan dalam Sistem Zonasi}

Menurut kementerian pendidikan dan kebudayaan (kemendikbud.go.id)[8] adanya kebijakan sistem zonasi dalam melaksanakan penerimaan didik baru yang berlandaskan pada landasan filosofis dan yuridris serta perubahan-perubahannya, terdapat harapan dan tuntutan dari masyarakat bagi perkembangan pendidikan. Arah kebijakan sistem zonasi ini ialah :

- Menjamin pemerataan pada akses pendidikan

- Memotivasi kreativitas pendidik dalam kelas menjadi heterogen

- Efisiensi jarak sekolah dengan calon peserta didik

- Melenyapkan ekslusivitas dan diskriminasi sekolah negeri

- Membantu menganalisis perhitungan kebutuhan dan distribusi guru

- Meningkatkan pengaksesan layanan pendidikan pada kelompok yang rentan

- Meningkatkan keragaman peserta didik di tiap sekolah

- Membantu pemerintah dalam memberikan bantuan agar lebih tepat sasaran

- Mendorong pemerintah daerah dalam pemerataan standar pendidikan

- Mencegah pemupukan kapasitas manusia berkualitas di suatu wilayah.

Sesuai dengan paparan Kementrian Pendidikan dan Kebudayaan dalam website nya (kemendikbud.go.id)[9], kebijakan sistem zonasi adalah untuk membentuk ekosistem pendidikan, ekosistem pendidikan berarti kebijakan zonasi dapat mendorong orang tua serta masyarakat untuk membantu guru dan sarana kependidikan lain (tripusat pendidikan) dalam meningkatkan kualitas pendidikan, sehingga ekosistem pendidikan akan terealisasi. lalu akan mampu menatakelola yang berbasis sekolah, yang berarti kepala sekolah sebagai manajer mampu melaksanakan tata kelola berbasis sekolah untuk memajukan sekolah, dan menjadikan sekolah rumah kedua bagi siswa serta menyejahterakan para guru dan sarana kependidikan lainnya.

\section{METODE PENELITIAN}

Metode penelitian ini adalah penelitian deskriptif kualitatif. Menurut sugiono (2003: 11) [10], metode penelitian deskriptif kualitatif yakni menggambarkan atau menjelaskan permasalahan yang ada dengan memberikan jawaban atas permasalahan. Penelitian ini berupaya untuk menggambarkan fakta dan fenomena yang terkait dengan kebijakan oleh kementrian pendidikan dan kebudayaan dan evaluasi dari dinas pendidikan pada penyelenggaraan sistem zonasi di Kota Pekanbaru.

Data sekunder diperoleh melalui observasi dan dokumentasi, data data yang diperoleh akan dibahas secara menyeluruh dengan dibandingkan dengan konsep teoriteori yang mendukung pembahasan terhadap permasalahan di penelitian ini. 
NAKHODA: JURNAL ILMU PEMERINTAHAN

JURNAL

Edisi Juli-Desember 2019 Volume: 18 Nomor: 2

ISSN : 1829-5827 | E-ISSN : 2656-5277

DOI : https://doi.org/10.35967/jipn

ILMU PEMERINTAHAN

https://nakhoda.ejournal.unri.ac.id/index.php/JIPN

\section{HASIL DAN PEMBAHASAN}

1. Peran Dinas Pendidikan Kota Pekanbaru Dalam Evaluasi Kebijakan Sistem Zonasi Tingkat Sekolah Menengah Atas

Kebijakan Sistem Zonasi untuk pelaksanaan penerimaan peserta didik baru merupakan kebijakan kementrian pendidikan dan kebudayaan republik indonesia untuk seluruh sekolah negeri di Indonesia termasuk Kota Pekanbaru. Tujuan penting dari kebijakan ini adalah untuk pemerataan pada kualitas pendidikan, menghemat waktu karena sekolah lebih dekat, menghemat biaya transportasi dan kondisi dari para peserta didik akan lebih segar karena tidak melalui perjalanan yang panjang dan mengurangi kemacetan.

Dinas Pendidikan Kota Pekanbaru adalah bagian dari pemerintahan Kota Pekanbaru dalam melaksanakan kebijakan dan teknis dibidang kependidikan dengan
Misi Pendidikan, yakni: "Menjadi Kota Pekanbaru Sebagai Pusat Pendidikan Yang Berkualitas, Berbudaya, dan Religius Untuk Mencapai Masyarakat Madani."

Dalam pembahasan ini, penulis akan menguraikan apa saja peran Dinas Pendidikan Kota Pekanbaru dalam mengevaluasi kebijakan sistem zonasi dari Kementrian Pendidikan dan Kebudayaan Republik Indonesia yang menimbulkan masalah dalam proses penerimaan peserta didik baru tingkat SMA di Kota Pekanbaru.

Dinas Pendidikan menetapkan radius untuk penerapan sistem zonasi sebagai salah satu peran nya, sistem zonasi memiliki radius 500 meter dari zona terdekat dari wilayah sekolah, data paduan bagi masyarakat untuk tingkat sekolah menengah atas sesuai zonasi yang ditetapkan oleh Dinas Pendidikan Provinsi Riau untuk Kota Pekanbaru adalah sebagai berikut :

Tabel. 1. Pembagian wilayah berdasarkan radius 500 M untuk tingkat SMA Kota Pekanbaru

\begin{tabular}{|c|c|}
\hline $\begin{array}{c}\text { SMA } \\
\text { PEKANBARU }\end{array}$ & $\begin{array}{c}\text { KECAMATAN } \\
\text { DAN KELURAHAN }\end{array}$ \\
\hline SMAN 1 & $\begin{array}{l}\text { - Kecamatan Lima puluh (Kel. Rintis, Sekip,Pesisir, Tanjung Rhu). } \\
\text { - Kecamatan Sukajadi (Kel. Pulau Karam). } \\
\text { - Kecamatan Sail (Kel. Suka Mulia). } \\
\text { - Kecamatan Pekanbaru Kota (Kel. Sumahilang, Sukaramai, Tanah Datar, } \\
\text { Tebing Tinggi, Kota Baru). }\end{array}$ \\
\hline SMAN 2 & $\begin{array}{l}\text { - Kecamatan Payung Sekaki (Kel. Labuh Baru Timur, Labuh Baru Barat, } \\
\text { Bandar Raya, Air Hitam). } \\
\text { - Kecamatan Sukajadi (Kel. Kedung Dari, Harjosari, Sukajadi). }\end{array}$ \\
\hline SMAN 3 & $\begin{array}{l}\text { - Kecamatan Rumbai (Kel. Umban Sari, Sri Meranti). } \\
\text { - Kecamatan Rumbai Pesisir (Kel. Lembah Damai RW1, RW2, RW3, RW5, } \\
\text { RW8, Limbungan Baru, Limbungan RW2, RW4, RW5, Meranti Pandak, } \\
\text { Rembah Sari RW1, RW2, RW11). }\end{array}$ \\
\hline
\end{tabular}


NAKHODA: JURNAL ILMU PEMERINTAHAN

Edisi Juli-Desember 2019 Volume: 18 Nomor: 2

ISSN : 1829-5827 | E-ISSN : 2656-5277

DOI : https://doi.org/10.35967/jipn

\begin{tabular}{|c|c|}
\hline SMAN 4 & $\begin{array}{l}\text { - Kecamatan Marpoyan Damai (Kel. Sidomulyo Timur kecuali RW4 dan } \\
\text { RW12, Maharatu, Perhentian Marpoyan) }\end{array}$ \\
\hline SMAN 5 & $\begin{array}{l}\text { - Kecamatan Marpoyan Damai (Kel. Sidomulyo Timur RW4, RW12, } \\
\text { Wonorejo kecuali RW1 dan RW5, Tangkerang Barat, Tangkerang Tengah). } \\
\text { - Kecamatan Sukajadi (Kmpg. Melayu, Kmpng Tengah, Jadi Rejo RW1, RW2, } \\
\text { RW3). }\end{array}$ \\
\hline SMAN 6 & $\begin{array}{l}\text { - Kecamatan Tenayan Raya ( Kel. Rejo Sari RW1, 2,3,4,13 dan 14, Bambu } \\
\text { Kuning, Industri Tenayan). }\end{array}$ \\
\hline SMAN 7 & $\begin{array}{l}\text { - Kecamatan Senapelan (Kel. Kampung Baru, Bandar, Kampung Dalam, Sago, } \\
\text { Padang Terubuk, Padang Bulan). } \\
\text { - Kecamatan Payung Sekaki (Kel. Tampan, Tirta Siak). }\end{array}$ \\
\hline SMAN 8 & $\begin{array}{l}\text { - Kecamatan Sail (Kel. Suka Maju, Cinta Raja). } \\
\text { - Kecamatan Sukajadi (Kel. Jadi Rejo RW4). } \\
\text { - Kecamatan Marpoyan Damai (Kel. Wonorejo RW1 dan RW5). } \\
\text { - Kecamatan Bukitraya (Kel. Tangkerang Utara, Tangkerang Labuai } \\
\text { RW1,2,3,4,5 dan 12, Tangkerang Selatan RW1,2,3,8,9,10, dan 11). } \\
\text { - Kecamatan Pekanbaru Kota (Kel. Simpang Empat). }\end{array}$ \\
\hline SMAN 9 & $\begin{array}{l}\text { - Kecamatan Lima Puluh (Kel. Rintis, Sekip, Pesisir, Tanjung Rhu). } \\
\text { - Kecamatan Sukajadi (Pulau Karam). } \\
\text { - Kecamatan Sail (Suka Mulia). } \\
\text { - Kecamatan Pekanbaru Kota (Kel. Sumahilang, Sukaramai, Tanah Datar, Kota } \\
\text { Tinggi dan Kota Baru). }\end{array}$ \\
\hline SMAN 10 & $\begin{array}{l}\text { - Kecamatan Tenayan Raya (Kel. Kulim, Mentangor, Pebatuan, Sialang } \\
\text { Rampai, Tangkerang Timur, Pematang Kapau). }\end{array}$ \\
\hline SMAN 11 & $\begin{array}{l}\text { - Kecamatan Tenayan Raya (Rejosari RW5,6,7,8,9,10,11,12,15,16 dan 17, } \\
\text { Sialang Sakti, Tuah Negeri, Melebung dan Bedah Lesung). }\end{array}$ \\
\hline SMAN 12 & $\begin{array}{l}\text { - Kecamatan Payung Sekaki (Kel. Sungai Sibam). } \\
\text { - Kecamatan Tampan (Tuah Karya, Tuah Madani, Simpang Baru, Air Putih, } \\
\text { Bina Widya, Tobek Godang). }\end{array}$ \\
\hline SMAN 13 & $\begin{array}{l}\text { - Kecamatan Rumbai (Kel. Muara Fajar Barat, Rantau Panjang, Rumbai Bukit, } \\
\text { Maharani, Agrowisata, Palas). }\end{array}$ \\
\hline SMAN 14 & $\begin{array}{l}\text { - Kecamatan Bukit Raya (Kel. Tangkerang Selatan RW4,5,6,7 dan 12, } \\
\text { Tangkerang Labuai RW6,7,8,9,10 dan 11, Air Dingin). } \\
\text { - Kecamatan Siak Hulu, Kampar (Perum. Barneo, GTU Labersa, Peputra } \\
\text { Indah, Perum. Duta Mas). }\end{array}$ \\
\hline SMAN 15 & $\begin{array}{l}\text { - Kecamatan Tampan (Kel. Tobek Godang, Sialang Mungguh, Sidomulyo } \\
\text { Barat, Delima). }\end{array}$ \\
\hline
\end{tabular}


NAKHODA: JURNAL ILMU PEMERINTAHAN

Edisi Juli-Desember 2019 Volume: 18 Nomor: 2

ISSN : 1829-5827 | E-ISSN : 2656-5277

DOI : https://doi.org/10.35967/jipn

https://nakhoda.ejournal.unri.ac.id/index.php/JIPN

\begin{tabular}{|l|l|}
\hline SMAN 16 & $\begin{array}{l}\text { Kecamatan Rumbai Pesisir (Kel. Limbungan RW 1,3,6,7,8,9,10,11 dan 12, } \\
\\
\end{array}$ \\
& Tebing Tinggi Okura, Lembah Damai RW4,6,7 dan 9, Lembah Sari RW \\
& $3,4,5,6,7,8,9,10,11,12,13$ dan 14, Sungai Ukai, Sungai Ambang). \\
\hline
\end{tabular}

Sumber : Data Disdik Riau 2019 (Disdik.riau.go.id) Diakses pada 1 November 2019

Berdasarkan data di atas dapat dilihat bahwa peran Dinas Pendidikan Riau dalam membagi radius sistem zonasi pada tingkat sekolah menengah atas di Kota Pekanbaru sudah sangat jelas, di bagi atas 16 sekolah dan 32 kecamatan di Kota Pekanbaru. meskipun pembagian tersebut kurang signifikan.

Pendidikan salah satu layanan dasar yang wajib sediakan kepada seluruh warga negara dan merupakan urusan konkuren pemerintah. Jalur zonasi yang dilaksanakan menegaskan bahwa tidak ada lagi nilai ujian nasional atau UN sebagai syarat utama dalam seleksi penerimaan peserta didik di Kota Pekanbaru. Pelaksanaan sistem zonasi pada PPDB di Kota Pekanbaru mendasar pada Permendikbud No 20 Tahun 2019, dan selanjutnya Dinas Pendidikan Kota Pekanbaru mengeluarkan Teknis PPDB yang mengatur secara rinci dan lengkap terkait sistem zonasi dari ketentuan umum, daftar pembagian zona, sampai ke jadwal pelaksanaan PPDB. Jalur zonasi dengan kuota penerimaan paling sedikit adalah $80 \%$ dari yang sebelumnya $90 \%$ wajib di selenggarakan masing-masing Pemerintah Daerah dan menerima calon didik yang berdomisili sesuai zona data Disdik. Kebijakan $80 \%$ tersebut termasuk kuota peserta didik yang tidak mampu dan penyandang disabilitas. Kebijakan tersebut menjadi salah satu peran pemerintah dalam memberi kesempatan bagi peserta didik untuk mendapatkan fasilitas yang sama dan layak di berbagai lapisan masyarakat dan dipersiapkan untuk menciptakan perubahan pada lingkungan dan perilaku individu atau kelompok.

Dinas Pendidikan dalam menjalankan kebijakan sistem zonasi bekerja sama dengan Dinas Kependudukan dan Pencatatan Sipil (dukcapil) untuk penetapan zonasi, dan memastikan sekolah yang berada dibawah naungan oleh pemerintah daerah di wilayah kerja masingmasing tidak menjual belikan bangku/ menitip peserta didik/ pemungutan liar dan hal-hal yang melanggar ketentuan peraturan perundang-undangan.

Dengan demikian, peran Dinas Pendidikan Kota Pekanbaru dalam mengevaluasi kebijakan sistem zonasi dari Kementrian Pendidikan dan Kebudayaan untuk tingkat menengah atas sudah sesuai dengan ketentuan yang berlaku.

\section{Dampak Evaluasi Kebijakan Pada Sistem Zonasi oleh Dinas Pendidikan Kota Pekanbaru Terhadap Pelaksanaan \\ Penerimaan Peserta Didik Baru Tingkat Menengah Atas \\ Pengaruh yang muncul baik positif} maupun negatif pada evaluasi kebijakan yang dilaksanakan oleh Dinas Pendidikan Kota Pekanbaru terhadap sistem zonasi pada tingkat sekolah menengah atas adalah 
sebagai berikut :

a) Preferensi jarak sebagai penentu utama Penerimaan Peserta Didik Baru. Pihak yang merasa dirugikan atau kontra terhadap evaluasi ini beranggapan bahwa hal tersebut masih sulit diterapkan, dengan melihat dari jumlah lulusan sekolah dan ketersediaan sekolah dimasing-masing daerah yang belum seimbang. Imbasnya, sekolah yang zona nya padat penduduk akan melebihi kuota dan sebaliknya.

b) Fundamen penerapan sistem zonasi. Adanya perbedaan penafsiran pada aturan zonasi penerimaan peserta didik baru yang mana mengakibatkan implementasinya tidak sesuai aturan. Di Kota Pekanbaru, sistem tidak dilaksanakan secara penuh yaitu dengan memberikan kuota dijalur prestasi bagi siswa yang memilikiprestasi dan nilai tinggi.

c) Penggunaan Surat Keterangan Tidak Mampu atau SKTM . Ketentuan pada sistem zonasi PPDB dengan memprioritaskan jarak membuat para wali murid yang berada di luar zonasi mengupayakan segala cara agar anaknya diterima di sekolah yang di harapkan.

d) Mengganti Kartu Keluarga. Sekolah mengutamakan calon didik yang memiliki kartu keluarga berdomisili satu wilayah dengan sekolah asal, hal itu membuat wali murid juga mengupayakan untuk mengubah Kartu Keluarga dan melanggar ketentuan syarat domisili minimal 1 tahun.

e) Melanggar hak anak Sesuai isi UU No. 20 Tahun 2003 tentang Sistem Pendidikan Nasional (UU Sisdiknas) pasal 5 ayat (1), sistem zonasi dianggap mengancam beberapa anak tidak mendapatkan bangku sekolah. Keterbatasan kuota yang tersedia di masing-masing sekolah negeri, jika pun bisa bersekolah tetapi harus masuk ke sekolah swasta dengan biaya tinggi.

f) Karakter pendidikan yang berbeda. Ketersediaan sumber daya manusia, fasilitas pendidikan dan jarak sekolah yang berbeda. Membuat stigma "sekolah favorit" masih melekat di diri masyarakat.

g) Kurangnya Sosialisasi. Pemerintah dan dinas terkait harus melakukan sosialisasi secara masif tentang kebijakan sistem zonasi agar muncul pemahaman yang komprehensif.

Hal-hal tersebut seharusnya menjadi langkah pemerintah bersama dinas terkait untuk mengevaluasi lebih baik lagi proses pemerataan pendidikan di Kota Pekanbaru pada tingkat sekolah menengah atas. Sistem ini diharapkan dapat menghilangkan "kasta" dalam pendidikan.

Dari hasil penelitian terhadap sistem zonasi yang di laksanakan di Kota Pekanbaru, juga terdapat dampak positifnya, yakni :

- Memperbaiki fasilitas dan kualitas pada tiap sekolah menengah atas agar sesuai dengan standar nasional, 
NAKHODA: JURNAL ILMU PEMERINTAHAN

JURNAL

Edisi Juli-Desember 2019 Volume: 18 Nomor: 2

ISSN : 1829-5827 | E-ISSN : 2656-5277

DOI : https://doi.org/10.35967/jipn

ILMU PEMERINTAHAN

https://nakhoda.ejournal.unri.ac.id/index.php/JIPN

yang akan merubah mindset masyarakat akan sekolah unggulan atau favorit.

- Mengubah kebijakan idealnya dengan proses evaluasi, dengan demikian kebijakan baru memperbaiki dan menyempurnakan ketimpangan pada kebijakan lama dan bukan menimbulkan masalah baru.

- Menetapkan sasaran yang hendak dicapai dan pastikan

\section{KESIMPULAN}

Kebijakan zonasi adalah program pemerintah dalam rangka pemerataan kualitas pendidikan. Dengan adanya program ini masyarakat akan lebih menghemat biaya transportasi, mengurangi kemacetan dan yang terpenting adalah semua akan merasakan pendidikan yang sama. Tetapi itu semua mampu diubah bila di dukung dengan fasilitas yang sudah memadai dan penyebaran sumber daya manusia yang sama. Nyatanya di Kota Pekanbaru, pelaksanaan sistem zonasi ini belum berjalan dengan baik ditambah lagi dengan stigma masyarakat akan sekolah favorit. Pro dan kontra dari kebijakan yang di keluarkan harus mampu di hadapi oleh pemerintah dan dievaluasi kembali.

Evaluasi kebijakan yang dilakukan harus sesuai dengan peraturan yang berlaku dan tidak melanggar hak-hak warga negara untuk merasakan pendidikan. Sosialisasi secara terus menerus akan sistem zonasi sangat di perlukan guna memberikan pehamahan secara baik dan tepat agar tidak terjadi kontra akan kebijakan yang di buat oleh Kementrian Pendidikan dan Kebudayaan Republik Indonesia.

\section{DAFTAR PUSTAKA}

A. Moore, M., Stewart, S., \& Hudock, "Institution building as a development assistance method.," SIDA, 1995.

Daryanto, Evaluasi Pendidikan. Jakarta: PT Asdi Mahasatya, 2001.

D. William N, Pengantar Analisis Kebijakan Publik, Kedua. Yogyakarta: Gadjah Mada University, 2000.

Sugiyono, "Metode Penelitian

Kuantitatif,Kualitatif dan R\&D," in ke-26, 2018.

\section{Peraturan Perundang - Undangan}

Republik Indonesia, "Undang-Undang Sistem Pendidikan Nasional No. 20 Tahun 2003," in Sekretariat Negara, 2003, doi: 10.16309/j.cnki.issn.10071776.2003.03.004.

Peraturan Menteri Pendidikan dan

Kebudayaan Republik Indonesia no 20 tahun 2019.

Peraturan Walikota Pekanbaru Nomor 92

Tahun 2016 Tentang Kedudukan,

Susunan Organisasi, Tugas dan

Fungsi Serta Tata Kerja Dinas

Pendidikan Kota Pekanbaru.

\section{Sumber Internet}

riau.com, "1 november 2019."

Kemdikbud, "Semua Bisa Sekolah! Zonasi Untuk Pemerataan Yang Berkualitas," 


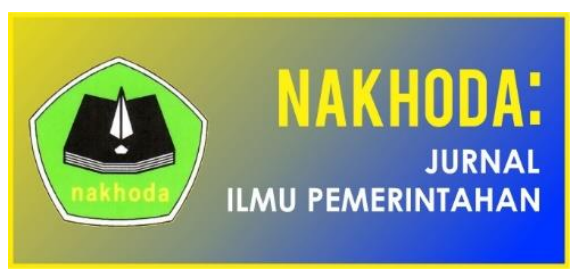

NAKHODA: JURNAL ILMU PEMERINTAHAN

Edisi Juli-Desember 2019 Volume: 18 Nomor: 2

ISSN : 1829-5827 | E-ISSN : 2656-5277

DOI : https://doi.org/10.35967/jipn

https://nakhoda.ejournal.unri.ac.id/index.php/JIPN

2018. .

Kemdikbud, "Sistem Zonasi Mempercepat

Pemerataan di Sektor Pendidikan,"

2019. 